\title{
INVESTIDORES INDIVIDUAIS NA BM\&FBOVESPA: UM ESTUDO COMPARATIVO ENTRE OS SETORES DE LISTAGEM E OS NÍVEIS DE GOVERNANÇA
}

BOTELHO, Luciano Henrique Fialho ${ }^{1}$ COSTA, Thiago de Melo Teixeira $\mathrm{da}^{2}$

\begin{abstract}
RESUMO: O mercado de capitais é um mecanismo importante para a capitação de recursos pelas empresas, além de ser uma opção para aplicadores, individuais ou organizações. No Brasil, a BM\&FBOVESPA é a maior bolsa de valores em operação. Com relação aos investidores individuais, percebe-se baixa participação, quando comparada a bolsas de outros países emergentes. O objetivo deste estudo foi analisar a participação de investidores pessoas físicas na BM\&FBOVESPA, especificamente dentro dos setores de listagem das empresas e dos segmentos de governança corporativa, verificando se algum setor ou segmento de governança corporativa se destaca em termos de participação de pessoas físicas. Ainda, procurou-se analisar o perfil dos aplicadores pessoas físicas e a evolução temporal da participação desses investidores na BM\&FBOVESPA. O referencial teórico aborda aspectos sobre governança corporativa, comportamento e preferência dos investidores e incentivos às aplicações no mercado de capitais. Com relação a metodologia, utilizou-se uma abordagem qualitativa e quantitativa com um objetivo exploratório e descritivo. Foram utilizados dados secundários disponibilizados pela BM\&FBOVESPA e a análise dos mesmos foi feita por meio de estatística descritiva, Regressão Linear Simples (RLS) e de análises gráficas baseadas no referencial teórico. Os resultados demonstraram que a evolução do número de pessoas físicas na bolsa de valores ocorreu concomitantemente com o momento econômico favorável, ainda que o setor de tecnologia da informação foi destaque em relação ao percentual de investidores pessoas físicas e que a listagem em segmentos superiores de governança corporativa não está diretamente relacionada com uma maior de participação de investidores individuais.
\end{abstract}

Palavras chave: Investidores pessoas físicas. Governança corporativa. BM\&FBOVESPA. Setores de listagem. Mercado acionário.

SUMMARY:The capital market is an important mechanism for capitation resources by enterprises, as well as being an option for operators, individuals or organizations. In Brazil, BM \& FBOVESPA is the largest stock exchange in operation. Regarding individual investors, one sees low turnout compared to bags of other emerging countries. The aim of this study was to analyze the participation of individual investors in the BM \& FBOVESPA, specifically within the list of sectors of business and corporate governance segments, checking whether any industry or corporate governance segment stands out in terms of participation of individuals. Still, he tried to analyze the profile of the individual applicators and temporal evolution of the participation of these investors at BM \& FBOVESPA. The theoretical framework addresses concerns about corporate governance, behavior and preference of investors and incentives to investments in the capital market. Regarding methodology, we used a qualitative and quantitative approach with an exploratory and descriptive goal. secondary data provided by BM \& FBOVESPA and the analysis of the data was made by means of descriptive statistics were used, Simple Linear Regression (RLS) and graphical analysis based on the theoretical framework. The results showed that the evolution of the number of individuals in the stock market occurred concurrently with the favorable economic times, although the information technology sector was highlighted in relation to the percentage of individual investors and the listing in the upper segments of governance corporate is not directly related to a greater share of individual investors.

Keywords: Individual investors. Corporate governance. BM\&FBOVESPA. List of sectors. Stock market.

RESUMEN: El mercado de capitales es un mecanismo importante para los recursos de capitación por las empresas, además de ser una opción para los operadores, los indivíduos u organizaciones. En Brasil, la BM \& FBOVESPA es la mayor bolsa de valores en funcionamiento. En cuanto a los inversores individuales, se observa

\footnotetext{
${ }^{1}$ Mestrando em Administração - Universidade Federal de Viçosa

${ }^{2}$ Professor do Programa de Pós-graduação em Administração - Universidade Federal de Viçosa
} 
una baja participación en comparación con las bolsas de otros países emergentes. El objetivo de este estudio fue analizar la participación de los inversores individuales en la BM \& FBOVESPA, específicamente dentro de la lista de los sectores de los segmentos de negocio y de gobierno corporativo, comprobar si cualquier industria o segmento de gobierno corporativo se destaca en cuanto a la participación de los individuos. Aún así, trató de analizar el perfil de los aplicadores individuales y evolución temporal de la participación de estos inversores en la BM \& FBOVESPA. El marco teórico que aborda las preocupaciones sobre el gobierno corporativo, el comportamiento y las preferencias de los inversores y los incentivos a las inversiones en el mercado de capitales. En cuanto a la metodología, se utilizó un enfoque cualitativo y cuantitativo con un objetivo exploratorio y descriptivo. datos secundarios proporcionados por la Bolsa y el análisis de los datos se realizó por medio de la estadística descriptiva se utilizaron, regresión lineal simple (SPI) y el análisis gráfico basado en el marco teórico. Los resultados mostraron que la evolución del número de individuos en el mercado de valores se produjo al mismo tiempo que los tiempos económicos favorables, aunque el sector de tecnología de la información se puso de relieve en relación con el porcentaje de inversores individuales y la inclusión en los segmentos superiores de gobierno corporativo no está directamente relacionado con una mayor parte de los inversores individuales.

Palablas clave: Los inversores particulares. Gobierno corporativo. BM\&FBOVESPA. Lista de los sectores. Mercado de valores.

\section{INTRODUÇÃO}

O Sistema Financeiro Nacional (SFN) possibilita o estabelecimento de contatos entre agentes deficitários e agentes superavitários de recursos financeiros. Assaf Neto (2008) ressalta que o SFN viabiliza a relação entre agentes carentes e agentes capazes de gerar poupança de recursos. Ademais, dentro do SFN existe o mercado financeiro que, para Pacheco e Oliveira (2010), é determinante para o crescimento econômico, pois facilita o acesso das empresas a recursos, estimulando a sua produção e consumo. As famílias também se beneficiam, pois terão melhores remunerações para os recursos poupados, além de acesso a financiamentos a juros mais baixos.

Com relação aos mercados que constituem o mercado financeiro, as perspectivas de aplicações de longo prazo são verificadas no mercado de capitais, segmento bastante relevante no que diz respeito ao desenvolvimento econômico, diante da sua estrutura diversificada em várias modalidades de financiamento para capital de giro e capital fixo. O mercado de capitais é constituído pelas bolsas de valores, pelas sociedades corretoras e pelas demais instituições financeiras autorizadas (ASSAF NETO, 2008). Uma relevante instituição participante desse mercado no Brasil é a Bolsa de Valores, Mercadorias e Futuros de São Paulo (BM\&FBOVESPA). Essa organização opera mercados de títulos, valores imobiliários e contratos derivativos, além de ser um destaque no mercado acionário brasileiro (ESCAVASSA; VIDOTTO, 2008).

O mercado acionário, para Escavassa e Vidotto (2008), permite a diluição dos riscos de novos investimentos e promove a democratização e a socialização do capital, a partir da redução da participação na propriedade das empresas, dando espaço para os pequenos poupadores. Dentro desse mercado, a BM\&FBOVESPA possui 10 setores de atuação para as empresas listadas, além de 5 níveis diferenciados de governança corporativa, nos quais as empresas se segmentam tendo como referência a utilização de instrumentos para a redução de potenciais conflitos de interesse entre acionistas ou entre os demais influenciados pela organização, com o objetivo de elevar a confiabilidade ao mercado acionária. As criações desses segmentos visam garantir segurança aos investidores e dessa forma, entre outros fatores, elevar a participação de aplicadores nesse mercado (BM\&FBOVESPA, 2015).

Um aspecto interessante no que diz respeito aos tipos de investidores que aplicam no mercado de ações da BM\&FBOVESPA, de acordo com o balanço de operações dessa instituição para o mês de abril 
de 2015, consiste na participação de investidores estrangeiros que é responsável por mais da metade da movimentação financeira nessa instituição brasileira, evidenciado ainda pelo elevado valor do Dólar em relação ao Real, seguida pelos aplicadores institucionais. Percebe-se baixas participações de alguns tipos de investidores, que são importantes para o desenvolvimento do mercado de capitais brasileiro, entre esses se encontram os investidores pessoas físicas.

Segundo dados da BM\&FBOVESPA (2015), apenas $14 \%$ do capital movimentado na BM\&FBOVESPA, em abril de 2015, são de aplicadores pessoas físicas, contra 52\% dos investidores estrangeiros e 34\% dos aplicadores institucionais. Escavassa e Vidotto (2008) ressaltam que esse número é resultado do perfil conservador do brasileiro, que opta pela poupança. Ainda, enquanto no Brasil, de acordo com a BM\&FBOVESPA (2015), 8\% do número total de investidores são pessoas físicas, nos Estados Unidos da América esses aplicadores representam cerca de $70 \%$ do total. Com relação a outros países, o Brasil também possui menos investidores pessoas físicas que a maioria dos emergentes, que possuem em média 5\% da população investindo na bolsa, contra 1\% dos brasileiros (BRANT, 2012).

$\mathrm{O}$ crescimento do número de participantes se torna importante para o desenvolvimento do mercado de capitais brasileiro e a entrada de investidores pessoa física, além disso, beneficia o mercado acionário, pois a participação desse tipo de investidor demonstra um maior nível de segurança desse mercado, a partir da determinação de medidas mais eficientes das empresas, no que concerne ao fortalecimento dos padrões de governança corporativa, na prestação de contas e responsabilidade na administração dos negócios (FILIPPO, 2008).

Ainda no que tange à participação de investidores pessoa física, outro ponto a se destacar é a preferência dos investidores por determinados investimentos. A opção por investir em uma empresa que possui um maior nível de governança corporativa, por exemplo, pode demonstrar a escolha por uma organização que, por disponibilizar maiores informações, acaba possuindo menor risco. Já a escolha de algum setor específico, pode ser devido a observação que esse determinado setor pode dar maior rentabilidade. Então, as escolhas e preferências dos investidores se darão por empresas que satisfaçam melhor a sua expectativa de risco e retorno, em uma análise racional (RAMBO, 2014).

Diante do exposto, a preocupação que norteia este estudo consiste na análise do comportamento e da participação de investidores individuais atuantes no mercado acionário da BM\&FBOVESPA, diante da importância dos investidores pessoas físicas para esse mercado e os números pouco expressivos disponíveis nesse sentido. A despeito, a análise de investidores individuais ou pessoas físicas não pode ser realizada sem considerar as assertivas propostas pelas finanças comportamentais, uma vez observada uma possível racionalidade limitada e imprevisibilidade no comportamento dos investidores, cuja as ações não necessariamente serão racionais (BARROS; FELIPE, 2015).

Este estudo, neste âmbito, vale-se de uma lacuna na análise de investidores individuais no Brasil, principalmente no que se refere à participação de aplicadores pessoa física por setor de listagem ou na relação entre os níveis de governança corporativa e os números de participação de pessoas físicas no mercado acionário da BM\&FBOVESPA. Diante do exposto, a inquietação de pesquisa deste estudo se pauta na análise dos investidores pessoas físicas no mercado de ações da BM\&FBOVESPA, surgindo assim a seguinte prerrogativa: dentro do mercado acionário da BM\&FBOVESPA existe algum setor de listagem e algum nível de governança corporativa que seja preferido pelos investidores pessoa física?

Dessa forma, o objetivo geral deste estudo consistiu em analisar a participação de investidores pessoa física na BM\&FBOVESPA. Especificamente, pretendeu-se:

- Demonstrar a evolução da participação de pessoas físicas de 2002 a 2015 e fatores podem influência nos números de participantes; 
- Apresentar o perfil do investidor pessoa física atuante na BM\&FBOVESPA (Idade, Gênero e Localização Geográfica);

- Observar se algum setor de listagem de empresas se destaca no que tange a participação de pessoas físicas, através das variáveis de participação de aplicadores individuais fornecidas pela BM\&FBOVESPA;

- Verificar se algum dos níveis de governança corporativa se destaca em termos de participação de investidores pessoas físicas, através das variáveis de participação de aplicadores individuais fornecidas pela BM\&FBOVESPA.

\section{REVISÃO DE LITERATURA}

\subsection{O Mercado Acionário e a BM\&FBOVESPA}

O Sistema Financeiro Nacional (SFN) consiste, segundo Fortuna (1997), em um conjunto de instituições que viabilizam a relação entre poupadores e aplicadores de recursos financeiros. A estruturação desse sistema, no Brasil, se deu a partir da lei da reforma bancária (1964), posteriormente pela lei do mercado de capitais (1965) e ainda com a lei de criação dos bancos múltiplos (1988) (ASSAF NETO, 2008).

Dentro do SFN encontra-se o Mercado de Capitais, o qual é o maior fornecedor de recursos para a economia, tendo em vista a ligação que efetua entre poupadores e investidores carentes de recursos de longo prazo. Dessa forma, o mercado de capitais assume o papel de ser um dos mais relevantes instrumentos de desenvolvimento econômico de um país (ASSAF NETO, 2008). Lanzarine et al (2011) sucinta que dentro do mercado de capitais encontramos o mercado de renda variável, no qual se oportuniza diversas formas de investimento, destacando-se a bolsa de valores.

Apesar de ainda ser pequeno em relação a mercados de países desenvolvidos, fazendo com que muitas empresas busquem recursos em bolsas de valores estrangeiras conforme coloca Botelho et al (2016), o mercado de capitais brasileiro conseguiu grandes avanços, ao se analisar o seu início no final dos anos 50 e começo dos anos 60. Naquela época, para Correa (2013), chamar o que existia de mercado de capitais era um exagero, diante dos raros clientes e pouquíssimas empresas atuantes, a maior bolsa brasileira estava localizado no Rio de Janeiro e a bolsa de Buenos Aires possuía mais relevância. Atualmente, a principal instituição do mercado de capitais brasileiro é a Bolsa de Valores, Mercadorias e Futuros de São Paulo (BM\&FBOVESPA), que opera mercados de títulos, valores imobiliários e contratos derivativos (LANZARINE et al, 2011).

Quando se refere ao mercado de capitais, o mercado acionário apresenta um maior incentivo a inovação econômica e a popularização e socialização do capital, diante da diluição dos riscos de novos investimentos (ESCAVASSA; VIDOTTO, 2008). Além disso, foi verificado pelo Banco Mundial, de acordo com BM\&FBOVESPA (2011), através de estudos com relação aos mercadores acionários, que existe uma correlação entre os indicadores desse mercado e o crescimento médio verificado nos países. Dessa forma, percebe-se que o mercado de ações, além de seguir o crescimento econômico, ele também contribui para taxas futuras de crescimento do capital, da produtividade e da renda per capita nos países (BM\&FBOVESPA, 2011).

Dentro do mercado acionário, a BM\&FBOVESPA possui 10 setores de atuação das empresas listadas (Bens Industriais, Construção e Transporte, Consumo Cíclico, Consumo não Cíclico, Financeiro e Outros, Matérias Básicos, Petróleo, Gás e Biocombustíveis, Tecnologia da Informação, Telecomunicações 
e Utilidades Públicas), onde estão listadas 514 empresas (BM\&FBOVESPA, 2015).

Já no que concerne aos segmentos de listagem das empresas, existem cinco níveis diferenciados que assumem um papel de acesso gradual a elevação de exigências de governança corporativa dentro do mercado de capitais, são eles o Bovespa Mais, Bovespa Mais nível 2, o mercado Nível 1, o Nível 2 e o Novo Mercado (BM\&FBOVESPA, 2015). De forma sucinta, os níveis Bovespa Mais e Bovespa Mais 2 são segmentos desenvolvidos para empresas de pequeno e médio portes, que podem efetuar a listagem da companhia sem necessariamente terem de ofertar ações em curto prazo. Ainda, as empresas desses dois primeiros segmentos possuem isenções em algumas taxas cobradas pela bolsa (BM\&FBOVESPA, 2015).

Para a entrada no nível 1, a organização deve passar a adotar uma maior relação com o investidor, com o fornecimento de informações que auxiliam na avaliação do valor da empresa, além de se comprometer a divulgar para os acionistas todos os acordos firmados com terceiros. Para o Nível 2, além de atender as exigências do Nível 1, outras práticas de governança corporativa devem ser adotadas, como conferir direito de voto restrito aos acionistas preferenciais, em situações de fusões e de aprovações de contratos entre a organização e o seu controlador. Como último segmento, em 2000, foi criado o Novo Mercado, onde se mantêm toda a regulamentação do Nível 2 e exigi que as organizações possuam no mercado apenas ações ordinárias, sendo o voto realizado de forma direta, além de outras situações (BM\&FBOVESPA, 2014).

Ademais, existem as empresas que não participam de nenhum nível de governança corporativa, destacando que a segmentação em um dos níveis não é obrigatória. Existe também o mercado de balcão tradicional, que consiste em um segmento de negociação onde os parâmetros de listagem são menos exigentes que o mercado da bolsa (BM\&FBOVESPA, 2015).

Em relação aos tipos de investidores que aplicam na BM\&FBOVESPA, existem os indivíduos, investidores pessoas físicas, e os aplicadores institucionais. O grande objetivo desses investidores consiste na busca por retornos satisfatórios a médio e longo prazo. No que tange aos investidores individuais, ou não profissionais para Neto (2009), o seu único objetivo é o seu próprio benefício, sem fins comerciais. Ademais, os aplicadores operam nas Bolsas por intermédio de corretoras ou distribuidoras de valores, instituições que executam as vontades dos seus clientes e recebem corretagens pelo serviço prestado (BM\&FBOVESPA, 2011).

\subsection{Governança Corporativa}

As preocupações no que tange a governança corporativa existem desde o início da década de 1990 nos Estados Unidos da América e na Europa. Já no Brasil, as primeiras medidas com esse enfoque ocorreram a partir do desenvolvimento do código brasileiro sobre governança corporativa, publicado em 1999 pelo Instituto Brasileiro de Governança Corporativa (GARCIA, 2005).

Vários pesquisadores conceituam governança corporativa, Andrade e Andrade (2005) ressaltam que governança corporativa representa o conjunto de princípios que visam reduzir possíveis conflitos de interesses dentro das organizações. Por outro lado, Correia et al (2011) apresenta a governança corporativa de forma mais abrangente, envolvendo estrutura de propriedade, remuneração dos dirigentes, composição do Conselho de Administração, proteção dos minoritários, além da transparência das informações e decisões.

A criação dos níveis de governança corporativa, citados anteriormente, geram maiores informações aos investidores e consequentemente mais segurança as aplicações, o que, por sua vez, eleva a participação de investidores. O maior avanço na bolsa de valores brasileira, até então, se deu com o crescimento do Novo Mercado, o segmento que mais protege o acionista. Diante desse novo segmento, 
ocorreu uma expansão do mercado de capitais nacional, com um aumento significativo dos valores que giram na BM\&FBOVESPA, uma vez que durante os anos da década de 2000, os valores praticados chegaram a marca de R $\$ 1,3$ trilhões, em 2009, com uma valorização de 562,5\% de 2001 a 2010 (COLOMBO; GALLI, 2010).

\subsection{Empresas Familiares e Incentivos à Aplicação no Mercado Acionário}

Este estudo procura analisar a participação de investidores pessoas físicas no mercado de ações da BM\&FBOVESPA. Diante disso, além do papel da governança corporativa, empresas de ascendência familiar, mesmo possuindo capital aberto, geralmente possuem a maior parte de suas ações pertencentes a membros da família, como demonstra o estudo KPMG (2014) destacando que $76 \%$ das empresas familiares conseguiram conservar a participação e ainda possuem maioria das ações e controle da organização, em todo mundo. Esses dados evidenciam que, no que tange a esse estudo, as empresas familiares se destacaram em torno da participação de indivíduos. Ademais, confirmando a relevância das empresas familiares, Sampaio et al (2014) identificou, através do seu estudo com empresas segmentadas no nível Novo Mercado da BM\&FBOVESPA, que 44,86\% das empresas, em 2010, possuíam controle familiar.

Empresas familiares são aquelas que possuem sucessão de poder de maneira hereditária, entre uma ou mais famílias (OLIVEIRA, 2010). O estudo KPMG (2014), vai ao encontro da definição anterior quando cita a gestão dessas empresas por várias gerações familiares, no entanto, não deixar de destacar a importância da existência de conselhos parcialmente compostos por membros não familiares.

Ainda, outros aspectos podem alavancar a participação de pessoas físicas nas organizações de capital aberto. Em 2002, o governo federal criou a possibilidade de o trabalhador aplicar o saldo do seu Fundo de Garantia por Tempo de Serviço (FGTS) em ações de empresas públicas através de fundos múltiplos de privatização. Esse panorama possibilitou a pessoas físicas o acesso a formas mais rentáveis de aplicação, com retornos que poderiam se tornar superior aos do FGTS. Ainda, levou cerca de 312 mil pessoas a realizarem sua primeira aplicação na bolsa de valores (DEBASTIANE, 2004).

Não obstante, a BM\&FBOVESPA possui várias alternativas de cursos, arquivos e exercícios interativos como forma de proporcionar a educação financeira e a elevação da participação de investidores no mercado acionário. Além disso, em 2010, a BM\&FBOVESPA lançou uma campanha visando explorar mais o nicho das pessoas físicas no mercado acionário brasileiro, através da criação do projeto "Quer ser Sócio?", com o objetivo de popularizar os investimentos por meio da educação financeira (RODRIGUES, 2012).

Outras instituições financeiras e de ensino também apresentam tais iniciativas, como a Fundação Bradesco e a Fundação Getúlio Vargas, com cursos online diversos. A Associação Brasileira das Entidades dos Mercados Financeiros e de Capital (ANBIMA), por sua vez, criou o selo Estratégia Nacional de Educação Financeira (ENEF), visando dar visibilidade a essas ações educativas, também como forma de desenvolver e disseminar os investimentos dos brasileiros no mercado de capital. Além disso, outra forma de elevar a participação utiliza pela BM\&FBOVESPA foi a criação de instrumentos que facilitam o acesso do investidor e a implementação do novo mercado e dos níveis de governança corporativa, visando dispor ao investidor maiores informações e transparência.

\subsection{Finanças Comportamentais e Investimentos de Investidores Individuais}

A existência de maiores informações e a educação financeira, apresentadas como incentivos aos aplicadores, no tópico anterior, ainda podem influenciar o investidor no momento de se aplicar na 
bolsa de valores. Entretanto, cada investidor possui um comportamento em relação ao risco e ao retorno esperado. Diante disso, estudos sobre finanças comportamentais são relevantes. A maioria dos investidores, segundo essa teoria, tomam as suas decisões a partir da incapacidade de analisar as situações com frieza e sem grandes informações disponíveis (BERNSTEIN, 2008). Percebe-se que questões comportamentais e a presença/ausência de informações são elementos que englobam as escolhas no momento de se investir. No que concerne aos investidores pessoas físicas, essas variáveis ligadas a aspectos culturais são mais visíveis, tendo em vista uma falta de especialização nessa área, situação incomum nos outros tipos de investidores.

Os Investidores... (2013) relata, a partir dos resultados de seu estudo, que a maioria dos brasileiros possuem o comportamento dominante de aversão ao risco, evidenciando assim a opção de se investir na poupança. Corroborando, Peterson $(2008$, p. 29) relata que "o modo como cada indivíduo lida com a mudança de suas condições financeiras depende da maneira como cria um significado pessoal para perdas e ganhos". Dessa forma, de acordo com Rambo (2014) citando Peterson (2008), fatores como personalidade, expectativas e condições de vida, influenciam na interpretação dos fatos e nas escolhas dos investidores. Diante das situações de oportunidade ou ameaças, as emoções perante o risco determinam como o investidor age, Rambo (2014, p.25) ressalta que se uma ameaça se torna realidade o investidor "como forma de reação pode-se entrar em pânico, fugir ou combater (lutar)".

Diante da importância dos aspectos emocionais no que tange as atuações dos investidores, Ferreira (2011) apresenta o significado de emoções para as atuações financeiras, segundo ele, a emoção consiste em impulsos e instintos que estão presentes nas ações dos aplicadores. Seguindo essa linha, Rambo (2014) apud Peterson (2008, p.26) apresenta a distinção entre as emoções antecipadas ou reativas dos investidores. $\mathrm{Na}$ maioria das vezes, os investidores amadores fazem seus investimentos abalizados pelas suas expectativas de preços favoráveis, diante dessa forma de ação, "as emoções antecipatórias positivas tendem a enviesar as expectativas dos investidores e acabam diminuindo sua percepção do risco". Ainda, aplicadores vendem suas ações "em reações a eventos (vendas reativas), seja por lucros maiores ou alguma notícia negativa, o que acontece como um resultado das emoções dos investidores e não como uma resposta ao planejamento racional".

\subsection{Estudos Similares}

Diante dos objetivos propostos para este estudo, no Quadro 1, são apresentados estudos que buscaram realizar análises semelhantes às realizadas neste trabalho, procurou-se evidenciar a aplicação e uso do método Regressão e a utilização de métodos robustos em estudos sobre finanças comportamentais.

Quadro 1: Estudos semelhares no uso de métodos de regressão.

(Continua)

\begin{tabular}{|l|l|l|l|l|}
\hline \multicolumn{1}{|c|}{ Estudo } & Autores & \multicolumn{1}{c|}{ Objetivo } & Metodologia & \multicolumn{1}{c|}{ Resultados } \\
\hline $\begin{array}{l}\text { Gestão da saúde } \\
\text { pública: análise } \\
\text { sobre os fatores } \\
\text { condicionantes do } \\
\text { desenvolvimento } \\
\text { humano. }\end{array}$ & $\begin{array}{l}\text { Matta et } \\
\text { al }\end{array}$ & $\begin{array}{l}\text { Procurou analisar } \\
\text { fatores, em } \\
\text { contexto municipal, } \\
\text { que influenciam na }\end{array}$ & $\begin{array}{l}\text { Regressão } \\
\text { Linear } \\
\text { Múltipla e } \\
\text { Análise de } \\
\text { qualidade de vida } \\
\text { local. }\end{array}$ & $\begin{array}{l}\text { Confirmou a relação de } \\
\text { explicação entre a situação } \\
\text { socioeconômica e a qualidade } \\
\text { de vida da população. }\end{array}$ \\
\hline
\end{tabular}


Quadro 1: Estudos semelhares no uso de métodos de regressão.

(Conclusão)

\begin{tabular}{|c|c|c|c|c|}
\hline Estudo & Autores & Objetivo & Metodologia & Resultados \\
\hline $\begin{array}{l}\text { Análise do } \\
\text { comportamento e } \\
\text { da percepção do } \\
\text { investidor em } \\
\text { relação ao risco sob } \\
\text { a ótica da teoria de } \\
\text { finanças } \\
\text { comportamentais. }\end{array}$ & $\begin{array}{l}\text { Walter, } \\
\text { Frega e } \\
\text { Silva } \\
(2010)\end{array}$ & $\begin{array}{l}\text { Avaliar as } \\
\text { alterativas e os } \\
\text { perfis de risco em } \\
\text { aplicações } \\
\text { financeiras de pós- } \\
\text { graduandos em } \\
\text { administração. }\end{array}$ & $\begin{array}{l}\text { Tabela } \\
\text { Cruzada e } \\
\text { Regressão } \\
\text { Linear } \\
\text { Múltipla. }\end{array}$ & $\begin{array}{l}\text { Os resultados apontaram a } \\
\text { falta de racionalidade nas } \\
\text { aplicações financeiras, sendo } \\
\text { que o retorno esperado foi o } \\
\text { que mais influenciou nas } \\
\text { decisões de investimento. }\end{array}$ \\
\hline $\begin{array}{l}\text { Finanças } \\
\text { comportamentais: } \\
\text { um estudo da } \\
\text { influência da faixa } \\
\text { etária, gênero e } \\
\text { ocupação na } \\
\text { aversão à perda. }\end{array}$ & $\begin{array}{l}\text { Melo } \\
(2010) .\end{array}$ & $\begin{array}{l}\text { Este estudo } \\
\text { objetivou observar } \\
\text { a influência de } \\
\text { gênero, idade e } \\
\text { ocupação na } \\
\text { aversão à perda dos } \\
\text { aplicadores. }\end{array}$ & $\begin{array}{l}\text { Regressão à } \\
\text { media }\end{array}$ & $\begin{array}{l}\text { O estudo trouxe evidências } \\
\text { estatísticas de indícios de } \\
\text { influência de todos os aspectos } \\
\text { analisados na aversão à perda } \\
\text { por parte dos indivíduos } \\
\text { estudados. }\end{array}$ \\
\hline $\begin{array}{l}\text { Finanças } \\
\text { comportamentais } \\
\text { no Brasil: um } \\
\text { estudo } \\
\text { comparativo. }\end{array}$ & $\begin{array}{l}\text { Rogers, } \\
\text { Segurat } \\
\text { o e } \\
\text { Ribeiro } \\
(2007) .\end{array}$ & $\begin{array}{l}\text { O estudo procurou } \\
\text { replicar estudos } \\
\text { seminais sobre as } \\
\text { finanças } \\
\text { comportamentais. }\end{array}$ & $\begin{array}{l}\text { Regressão à } \\
\text { média }\end{array}$ & $\begin{array}{l}\text { Foi verificada a falta de } \\
\text { racionalidade nas tomadas de } \\
\text { decisões de investimento, } \\
\text { corroborando com a teoria do } \\
\text { Prospecto e a influência de } \\
\text { vieses culturais nas aplicações } \\
\text { financeiras. }\end{array}$ \\
\hline $\begin{array}{l}\text { O perfil das } \\
\text { pesquisas em } \\
\text { finanças no Brasil. }\end{array}$ & $\begin{array}{l}\text { Leal, } \\
\text { Oliveira } \\
\text { e Soluri } \\
(2003)\end{array}$ & $\begin{array}{l}\text { Este estudo teve } \\
\text { como objetivo fazer } \\
\text { um levantamento } \\
\text { sobre os estudos em } \\
\text { finanças no Brasil. }\end{array}$ & $\begin{array}{l}\text { Bibliometria; } \\
\text { Regressão } \\
\text { Linear } \\
\text { Múltipla. }\end{array}$ & $\begin{array}{l}\text { Foram destacadas as ligações } \\
\text { acadêmicas dos autores, a } \\
\text { quantidade de autores por } \\
\text { estudo, a concentração dos } \\
\text { estudos nas regiões sul e } \\
\text { sudeste, além de outras } \\
\text { descobertas. }\end{array}$ \\
\hline $\begin{array}{l}\text { Determinantes de } \\
\text { estrutura de capital } \\
\text { no mercado } \\
\text { brasileiro: análise } \\
\text { de regressão com } \\
\text { painel de dados no } \\
\text { período } 1999-2003 .\end{array}$ & $\begin{array}{l}\text { Nakamu } \\
\text { ra et al } \\
(2007) \text {. }\end{array}$ & $\begin{array}{l}\text { O presente estudo } \\
\text { teve como objetivo } \\
\text { principal analisar } \\
\text { os fatores } \\
\text { influentes no } \\
\text { endividamento das } \\
\text { empresas de capital } \\
\text { aberto no Brasil, } \\
\text { entre } 1999 \text { e } 2003 \text {. }\end{array}$ & $\begin{array}{l}\text { Regressão } \\
\text { Linear } \\
\text { Múltipla e } \\
\text { análises } \\
\text { econométrica } \\
\text { s. }\end{array}$ & $\begin{array}{l}\text { Em consonância com os } \\
\text { estudos na área, os resultados } \\
\text { demonstraram relação direta } \\
\text { entre o endividamento, o } \\
\text { tamanho da empresa e o } \\
\text { crescimento das vendas. Por } \\
\text { outro lado, a rentabilidade e a } \\
\text { expectativa externa de } \\
\text { crescimento apresentaram } \\
\text { relação negativa à } \\
\text { alavancagem. }\end{array}$ \\
\hline
\end{tabular}

Fonte: Elaborado pelo Autor

\section{PROCEDIMENTOS METODOLÓGICOS}

A fim de atingir os objetivos propostos, o presente estudo utilizou uma abordagem qualitativa, pois essa vertente, segundo Vieira (2006, p. 18), "oferece descrições ricas e bem fundamentadas, além de explicações sobre processos em contextos locais identificáveis". Ainda, adotou uma abordagem quantitativa, tendo em vista o uso de procedimentos estatísticos para se alcançar os resultados. Quanto ao objetivo, esta pesquisa pode ser classificada como exploratória, uma vez que se propôs a descobrir relações entre setores e o nível de participação de investidores pessoas físicas, e descritiva diante da 
descrição da atuação dos investidores individuais.

Quanto aos dados, utiliza-se de dados secundários divulgados pela BM\&FBOVESPA. Os dados referentes a participação de pessoas físicas no capital social das empresas foram coletados entre 31 de julho e 20 de agosto de 2015, já os dados relativos ao número de participantes totais da BMF\&BOVESPA e o perfil dos investidores foram colhidos em outubro de 2015. Os dados referentes a participação de investidores no capital social por empresas, utilizados para analisar os setores e segmentos, são disponibilizados pela BMF\&BOVESPA desconsiderando os acionistas com menos de 5\% de participação nas organizações. Dessa forma, foram calculadas as participações absolutas, através do percentual em relação as informações disponíveis, desconsiderando os percentuais abaixo de 5\% supracitados.

É importante destacar, conforme citado anteriormente, que a pesquisa se dá em termos de participação das pessoas físicas no capital social das empresas, não apenas na quantidade numérica de pessoas físicas participantes, para o terceiro e quarto objetivos específicos. No que concerne aos objetivos específicos que procuram analisar à evolução no número de pessoas físicas e apresentar o perfil dos investidores individuas, a avaliação se pauta no número de pessoas físicas em quantidade numérica.

Com relação a análise dos resultados, no que tange à evolução da participação de pessoas físicas na BM\&FBOVESPA, no período de 2002 a 2015, e no que concerne à análise dos setores em termos de participação de pessoas físicas, utilizou-se da estatística descritiva, cálculo de médias, desvio padrão e amplitude. Ainda, adotou-se a análise gráfica, de cunho qualitativo, com suporte no referencial teórico abordado.

Ademais, foi realizada a partir do programa Stata® Statistics/Data Analysis 11.2 uma Regressão Linear Simples para estimar a equação do modelo de Regressão Linear Simples (RLS), com o objetivo de mensurar a relação funcional entre o segmento de governança corporativa (SGC - variável independente) e a participação de pessoas físicas (PPF - variável dependente).

A regressão linear simples consiste em uma análise para verificar como uma alteração na variável X (variável independente) pode afetar a variável Y (variável dependente). Dessa forma, busca predizer valores de uma variável dependente em função de uma variável independente (HAIR Jr., 2009). A equação da RLS é expressa abaixo:

$$
\mathrm{PPF}_{\mathrm{i}}=\alpha+\beta \cdot \mathrm{SGC}_{\mathrm{i}}+\mathrm{e}_{\mathrm{i}}
$$

Em que:

$\mathrm{PPF}_{\mathrm{i}}=$ Participação de Pessoas Físicas de cada empresa i;

$\alpha=$ coeficiente linear;

$\beta=$ coeficiente angular;

$\mathrm{SGC}_{\mathrm{i}}=$ Segmentos de Governança Corporativa de cada empresa i e $\mathrm{e}_{\mathrm{i}}=$ erro aleatório.

A relação procurada tange em analisar as variações entre os níveis de governança corporativa e o número de indivíduos, entre julho e agosto de 2015, que aplicam em empresas listadas nesses níveis. Dessa forma, busca-se verificar se um nível mais elevado de governança corporativa, Quadro 1, possui maior participação de pessoas físicas.

Para tal regressão, foram atribuídos valores aos níveis de governança corporativa, conforme o quadro 1: 
Quadro 2: Valores atribuídos aos segmentos de GC.

\begin{tabular}{|c|c|}
\hline Segmento/Nível de governança & Valores Atribuídos \\
\hline Sem nível & 1 \\
\hline Mercado de Balcão & 2 \\
\hline Bovespa Mais & 3 \\
\hline Nível 1 & 4 \\
\hline Nível 2 & 5 \\
\hline Novo Mercado & 6 \\
\hline
\end{tabular}

Fonte: Elaborado pelo Autor

Com a realização da RLS pretendeu-se avaliar o quão o nível de governança corporativa de determinada empresa influencia no percentual de participação de pessoas físicas no capital acionário da referida empresa. Salienta-se que o modelo de RLS considera o Método dos Mínimos Quadrados Ordinários (MQO), que busca à minimização das diferenças entre os valores estimados e os valores reais. Em relação à significância do modelo de RLS, realizou-se o teste P-valor, para avaliar os coeficientes estimados isoladamente, e o teste $\mathrm{F}$, para avaliar o poder de explicação do modelo como um todo.

\section{RESULTADO E DISCUSSÃO}

\subsection{Evolução na Participação de Pessoas Físicas na BM\&FBOVESPA}

A partir dos resultados encontrados, observa-se um crescimento da participação de pessoas físicas nos mercados da BM\&FBOVESPA, de 2002 a setembro de 2015, de 85.249 participantes a 558.759, uma elevação de $655 \%$ aproximadamente, figura 1.

Figura 1: Participação de pessoas físicas.

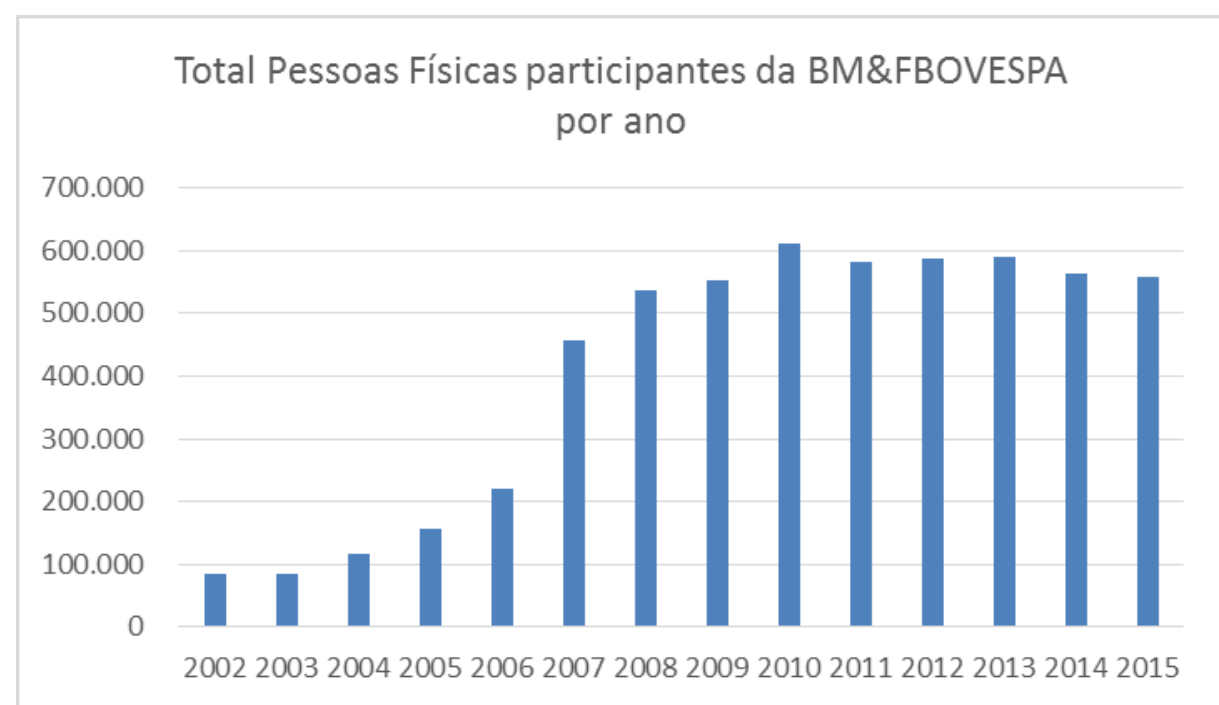

Fonte: BM\&FBOVESPA 2015.

Nesse período em estudo, ocorreram diversas situações que foram determinantes para a elevação citada. De acordo com Colombo e Galli (2010), a criação do segmento de governança corporativa Novo 
Mercado em 2000, foi um feito positivo para o crescimento da BM\&FBOVESPA e também para a elevação da participação pessoas físicas. Além disso, em 2002 o governo federal lançou a possibilidade de pessoas físicas aplicarem o seu Fundo de Garantia por Tempo de Serviço (FGTS) em ações de empresas mistas, o que geraria, a princípio, maiores retornos aos trabalhadores, além de ser um impulso para o mercado acionário brasileiro. Essas duas construções foram importantes para a evolução de pessoas físicas na BM\&FBOVESPA nesse período analisado, principalmente entre os anos de 2002 a 2005, em que ocorreu crescimento de $82,03 \%$.

Verifica-se, entretanto, que os maiores avanços ocorreram entre 2006 e 2010, de 219.634 para 610.915 investidores, concomitantemente nos anos em que o Produto Interno Bruto (PIB) brasileiro obteve bons crescimentos, destacando-se o ano de 2010 cujo o PIB cresceu 7,6\%, de acordo com o Instituto Brasileiro de Geografia e Estatística (IBGE), maior aumento no período analisado, e ano em que o número de investidores pessoas físicas apresentou o seu maior valor histórico, 610.915 mil aplicadores. A maior renda da população, o bom momento da economia e da bolsa nacional culminaram no crescimento do número de investidores pessoa física na BM\&FBOVESPA.

Ademais, entre 2006 e 2010, o Brasil obteve baixos níveis de inflação, uma média de aproximada 5\% ao ano, segundo dados do IBGE, se comparada ao histórico brasileiro. A inflação controlada e baixa também motiva a aplicação de investidores do mercado de ações e de renda variável como um todo, uma vez que os mercados de renda fixa atrelados à inflação perdem um pouco da sua rentabilidade, que, normalmente, é bastante elevada no Brasil.

A partir de 2011 a economia começa a diminuir seu ritmo e o número de investidores pessoas físicas sofre uma leve queda em 2014 e 2015, após ficar estável entre 2011 e 2013. Nesse momento, com a economia desacelerada e a elevação da inflação, a queda fica eminente, entretanto, a partir de 2010 surgiram programas na área pública e também na área privada dedicados à disseminação da educação financeira, como forma de incentivar a população a aplicar seus recursos em outros investimentos além da poupança, como a própria BM\&FBOVESPA que lançou a companha "Quer ser Sócio?”, relatada por Rodrigues (2012) como relevante no sentido de dar educação financeira. A Fundação Bradesco, a Fundação Getúlio Vargas, além da Associação Brasileira das Entidades dos Mercados Financeiros e de Capital (ANBIMA) criaram diversos projetos que foram importantes para a manutenção do nível de participantes nesse período.

Diante disso, percebe-se que a participação de aplicadores pessoa física pode estar ligada ao estado geral da economia e da própria bolsa de valores. Além disso, vários programas criados nesse período também contribuíram para essa evolução. Ademais, ainda com essa evolução, o número de investidores pessoa física é baixo quando comparado a outros países. Utilizando-se de dados desse estudo, podemos calcular que o número de pessoas físicas que investem na BM\&FBOVESPA representa apenas $0,28 \%$ da população brasileira. Em contrapartida a média nos países emergentes chega a 5\% das populações (BRANT, 2012).

\subsection{O Perfil dos Acionistas Pessoas Físicas atuantes na BM\&FBOVESPA.}

A BM\&FBOVESPA divulga, periodicamente, o perfil dos acionistas pessoa física. De acordo com o levantamento de setembro de 2015, a participação da mulher em aplicações nessa instituição representava cerca de $25 \%$ do total. Quando se faz uma análise temporal, observa-se um crescimento entre 2002 e 2015, passando de 17,63\% em 2002, 15.030 mulheres, para 25,00\% em setembro de 2015, 133.613 mulheres. Apesar desse número ainda ser bastante baixo, percebe-se que vem ocorrendo uma evolução da participação das mulheres. Entretanto, políticas com incentivo a população feminina devem ser mais 
efetivas devido ao baixo número de aplicadoras.

No que tange a idade dos aplicadores, o Quadro 3 apresenta o total de aplicadores por faixa etária, para setembro de 2015.

Quadro 3: Faixa etária dos aplicadores pessoa física

\begin{tabular}{|c|c|c|}
\hline Faixa etária & Total & Percentual \\
\hline Até 15 anos & 1.867 & 0,034 \\
\hline De 16 a 25 anos & 12.891 & 2,300 \\
\hline De 26 a 35 anos & 108.422 & 19,404 \\
\hline De 36 a 45 anos & 133.334 & 23,869 \\
\hline De 46 a 55 anos & 112.587 & 20,159 \\
\hline De 56 a 65 anos & 99.806 & 17,870 \\
\hline Maior de 66 anos & 89.852 & 16,080 \\
\hline TOTAL & $\mathbf{5 5 8 . 7 5 9}$ & $\mathbf{1 0 0 , 0 0 0}$ \\
\hline
\end{tabular}

Fonte: BM\&FBOVESPA (2015)

Para os jovens de 16 a 25 observa-se uma pequena participação, cerca de 2,3\% do total. Essa faixa etária, na maioria das vezes, representa pessoas que ainda são estudantes ou estão começando sua vida economicamente ativa ou que não tem conhecimentos sobre o mercado de capitais, a educação financeira na escola poderia favorecer a participação desse perfil de investidor.

Os investidores de idade entre 26 e 55 anos representam 63,42\% dos aplicadores pessoas físicas, esse grupo contempla os investidores mais focados em sua vida financeira e que procuram adquirir mais bens e ter melhores retornos. Maiores de 56 anos também possuem um bom nível de investimento, contemplando $33,88 \%$.

Também foi analisado neste estudo os estados onde se concentra a maioria dos aplicadores pessoas físicas do mercado de capitais da BM\&FBOVESPA, tabela 2. Dessa forma, verifica-se que os estados de maior desenvolvimento econômico concentram a maioria dos investidores pessoas físicas.

Figura 2: Participação de pessoas físicas por estado.

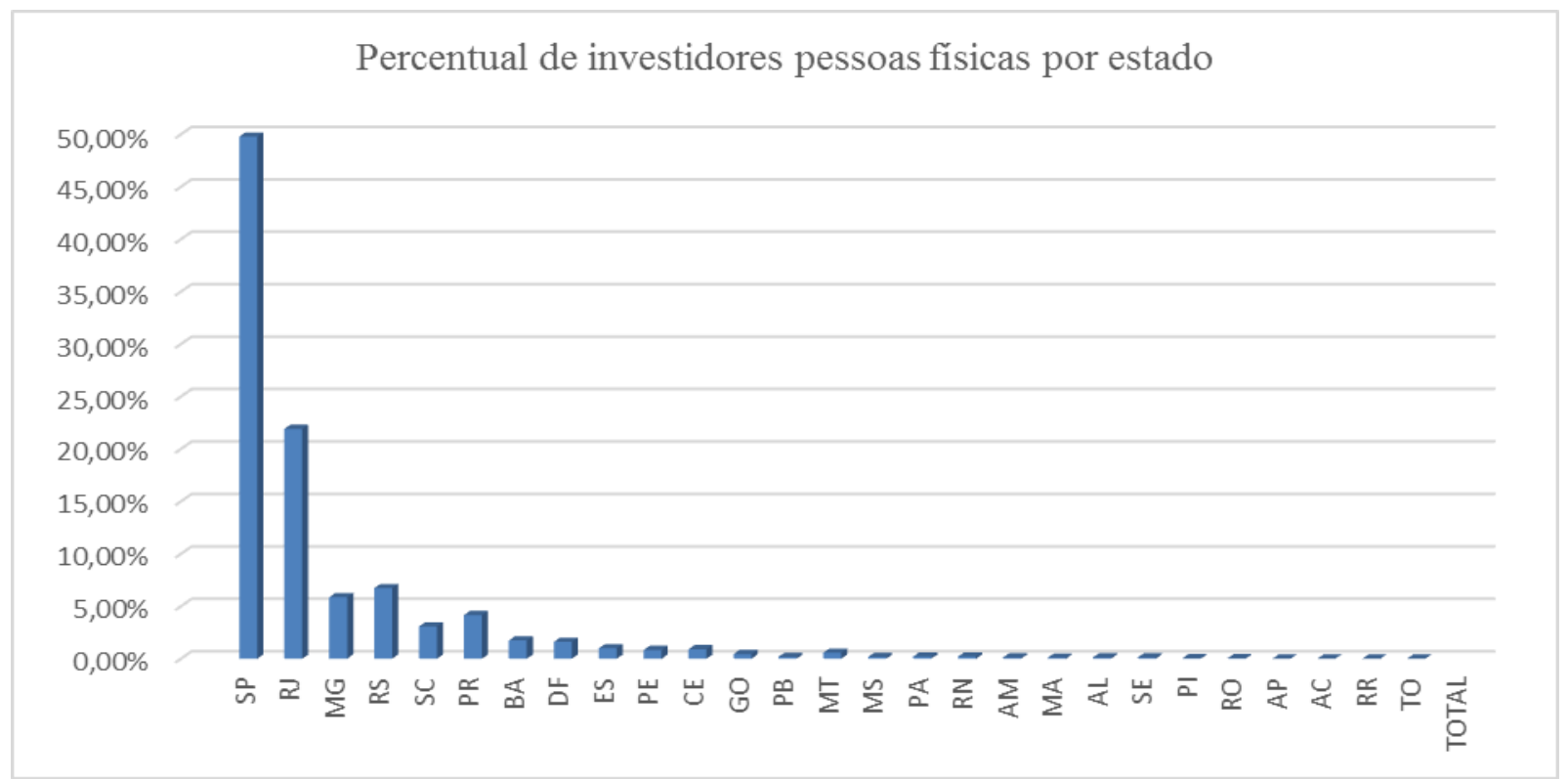

Fonte: BM\&FBOVESPA (2015). 
Os estados da região sudeste são responsáveis por $75 \%$ dos investidores, sendo que São Paulo contempla quase $50 \%$ do total. Ainda, os menores percentuais estão nas regiões norte e nordeste, os estados do Amapá, do Acre e Roraima possuem apenas 0,01\% dos participantes, cada um, menores participações entre todos os estados. Diante desses resultados, percebe-se mais uma vez a forte ligação entre o desenvolvimento econômico e a participação de pessoas físicas, tendo em vista que o estado de São Paulo e a região sudeste apresentar um desenvolvimento econômico superior aos outros estados e as outras regiões.

\subsection{Participação de Pessoas Físicas e os Setor de atuação das organizações}

Neste capítulo é discorrido sobre a participação dos investidores pessoas físicas por setor de atuação das empresas na BM\&FBOVESPA. O Quadro 4 traz a participação de pessoas físicas no capital social de cada setor, para esse quadro foi calculada a média ponderada para cada setor de atuação, de acordo com o número de empresas.

Nesse sentido, o setor de Tecnologia da Informação apresentou maior participação de acionistas pessoas físicas. Essas empresas normalmente possuem maiores investimentos em inovações, além de estarem no foco da mídia, tendo em vista o elevado número de seguidores, de adeptos as redes sociais e o crescente número de sites de compra. O setor de tecnologia contempla as maiores empresas no mundo em valor de mercado, Renick e Satariano (2014) relatam essa tendência está também na bolsa de valores americana, destacando a Aplle inc. e a Microsoft Corp.. como maiores recebedoras de investidores nos Estados Unidos da América.

Em segundo lugar aparecem as empresas do setor de Consumo Cíclico, alavancadas principalmente pelas organizações do subsetor educacional e também pelo subsetor de tecidos, vestuários e calçados. Em seguida o setor de Materiais Básicos se destaca com 20,74\% de participação de pessoas físicas, nesse setor encontra-se grandes empresas da mineração, de fabricação de artefatos de aço e ferro, além de empresas exploradoras de madeira e produtoras de papel, organizações muito ativas na economia brasileira, principalmente na exportação de seus produtos. Posteriormente, surgem as empresas do setor de Bens Industriais que são responsáveis pela fabricação de materiais de transporte, equipamentos elétricos e maquinas e equipamentos.

Quadro 4: Participação de Pessoas Físicas por setor.

\begin{tabular}{|l|c|c|}
\hline Setor & N. de Empresas & Part. P.F.por Setor (\%) \\
\hline Tecnologia da Informação & 10 & 29,93 \\
\hline Consumo cíclico & 66 & 21,61 \\
\hline Materiais Básicos & 38 & 20,74 \\
\hline Bens Industriais & 33 & 15,39 \\
\hline Consumo não cíclico & 41 & 12,43 \\
\hline Financeiro e Outros & 140 & 11,35 \\
\hline Construção e Transporte & 72 & 10,93 \\
\hline Petróleo, gás e biocombustível & 6 & 2,78 \\
\hline Telecomunicações & 69 & 0,52 \\
\hline Utilidades Públicas & 69,43 \\
\hline \multicolumn{2}{|c|}{ Participação média na BM\&FBOVESPA } & 12,611 \\
\hline \multicolumn{2}{|c|}{ Desvio Padrão } & 9,720536622 \\
\hline \multicolumn{2}{|c|}{ Amplitude Total } & 29,50 \\
\hline
\end{tabular}

Fonte: BM\&FBOVESPA (2015). 
Com relação aos três setores citados anteriormente, Consumo Cíclico, Materiais Básicos e Bens Industriais, pode-se destacar, ainda, o aspecto de empresa familiar que está presente em várias das 137 empresas desses setores. Empresas de ascendência familiar, mesmo possuindo capital aberto, ainda possuem boa parte de suas ações pertencentes a membros da família, como demonstra o estudo KPMG (2014) o qual concluiu que $76 \%$ das empresas familiares conseguiram conservar a participação e ainda manter o controle da organização, em todo mundo. Ainda, Sampaio et al (2014) relata que $44,86 \%$ das empresas segmentadas no Novo Mercado da BM\&FBOVESPA, em 2010, possuíam controle familiar. O controle familiar eleva a participação de pessoas físicas no capital social das empresas, o que pode explicar em partes as maiores participações nesses setores, em relação à média geral de 12,61\% .

No que concerne aos setores de Consumo Não Cíclico e Financeiro e Outros, apesar da existência de empresas com elevadas participações de pessoas físicas, percebe-se que a maioria do capital social das organizações em geral são de investidores estrangeiros, que, segundo a BM\&FBOVESPA (2015) em seu boletim de abril, são os maiores investidores na bolsa brasileira.

O setor de Construção e Transporte apresenta uma particularidade que afeta a sua classificação neste estudo. Dentro desse setor, encontra-se o subsetor de construção e engenharia, que apresenta boa participação de investidores pessoas físicas, com uma característica também familiar, se analisado isoladamente possuiria $22,33 \%$ de participação de pessoas físicas, percentual superior à média, 12,61\% . Entretanto, o subsetor transporte quando analisado isoladamente possui apenas 2,09\% de participação de pessoas físicas. Destaca-se que nesse subsetor existem as empresas responsáveis pela exploração de rodovias e ferrovias, que que trabalham através das concessões públicas do governo. A formação dessas empresas consiste, na maioria das vezes, por união de outras empresas para a formação da organização responsável pela exploração, o que não abre espaço para o investidor individual.

No que tange aos setores de menor participação de pessoas físicas, os setores de Petróleo, Gás e Biocombustível, Telecomunicações e Utilidades Públicas, a maioria das empresas são estrangeiras e não possuem nenhuma participação de pessoas físicas, principalmente nos setores de Petróleo, Gás e Biocombustíveis e de Telecomunicações. $\mathrm{O}$ setor de utilidades públicas, possui várias sociedades de economia mista e também empresas exploradoras de concessões públicas.

Ainda, no Quadro 4, é apresentada a média de participação de pessoas físicas na BM\&FBOVESPA, que foi calculado somando todos os valores encontrados e dividindo pelo total de empresas, chegando a uma média geral, importante para a análise dos resultados. Ademais, a amplitude total de $29,50 \%$ representa a variação entre o maior percentual de participação encontrado, setor de Tecnologia da Informação com $29,93 \%$, e o setor de menor participação de pessoas físicas, Utilidade Pública com apenas $0,43 \%$. O desvio-padrão demonstra a variações dos percentuais dos setores em relação à média, o valor encontrado, 9,72 de dispersão dos percentuais é alta, confirmando o resultado da amplitude e demonstrando a grande variação entre os setores de listagem da BM\&FBOVESPA, explicado pelas várias situações nas quais se encaixa cada setor.

Utilizando-se a média de todos os setores, apresentada no quadro 3, foi construído o Quadro 5, o qual traz uma comparação entre o total de participação de pessoas físicas, apresentado no item 1 deste capítulo, e total do capital social pertencente a esse tipo de investidor nas empresas listadas na BM\&FBOVESPA. 
Quadro 5: Comparativo quantidade de PF e capital social pertencente as PF.

\begin{tabular}{|c|c|c|c|c|}
\hline Tipo de invest. & Quantidade de Invest. & $\%$ & Capital Social Total & $\%$ \\
\hline Pessoas Físicas & 558.759 & $95,79 \%$ & $172.157 .698 .174,81$ & 12,61 \\
Pessoas Jurídicas & 24.538 & $4,21 \%$ & $1.193 .089 .710 .031,43$ & 87,39 \\
\hline TOTAL & 583.297 & $100,00 \%$ & $1.365 .247 .408 .206,24$ & 100 \\
\hline
\end{tabular}

Fonte: BM\&FBOVESPA (2015)

O número de pessoas físicas é muito superior ao número de pessoas jurídicas, entretanto a maioria do capital social pertence aos proprietários pessoas jurídicas, que por sua vez detém, na maioria das vezes, mais recursos para investir e maiores conhecimentos técnicos sobre o mercado acionário.

\subsection{Participação de Pessoas Físicas nos Segmentos de Governança Corporativa da BM\&FBOVESPA}

Para atender o objetivo específico de verificar se algum segmento de governança corporativa se destaca no que tange ao número de investidos pessoas físicas que aplicam nas empresas listadas neles, são apresentados os números de empresas pertencente a cada segmento de governança corporativa e o percentual de pessoas físicas que aplicam em cada um desses segmentos, Quadro 6.

Quadro 6: Participação de Pessoas Físicas por segmento de governança corporativa.

\begin{tabular}{|c|c|c|}
\hline Segmento/Nível & $\begin{array}{c}\text { Número de empresas } \\
\text { listadas por segmento }\end{array}$ & $\begin{array}{c}\text { Percentual médio de P.F. } \\
\text { por segmento }\end{array}$ \\
\hline SEM SEGMENTO & 232 & $47,57 \%$ \\
\hline Novo Mercado (NM) & 135 & $32.58 \%$ \\
\hline Nível 1 (N1) & 30 & $5.94 \%$ \\
\hline Nível 2 (N2) & 19 & $5.75 \%$ \\
\hline Mercado de Balcão (MB) & 59 & $4.34 \%$ \\
\hline Bovespa Mais (MB) & 8 & $3.82 \%$ \\
\hline TOTAL & 483 & $100.00 \%$ \\
\hline
\end{tabular}

Fonte: BM\&FBOVESPA (2015)

Dessa forma, é verificado que a maioria das empresas não pertencem a nenhum nível de governança corporativa, ainda que, o investidor pessoa física, na maioria das vezes, não observa o nível de governança corporativa da empresa no momento de aplicar nela, uma vez que as empresas que não estão listadas em nenhum segmento de governança corporativa são aquelas que mais recebem investimentos de pessoas físicas, onde 47,57\% dos investidores pessoas físicas da BM\&FBOVESPA aplicam em empresas não segmentadas em níveis de governança corporativa. Com relação aos segmentos, o segmento Novo Mercado apresenta maior participação de pessoas físicas.

Os princípios de governança corporativa visam evitar conflitos entre acionistas e administrados das organizações, além de fornecer mais informações aos investidores (ANDRADE; ANDRADE, 2005). A escolha por empresas que não seguem regras de governança corporativa implica em dizer que os investidores pessoas físicas, em sua maioria, podem não estar preocupados quanto à segurança de seu investimento, as escolhas se pautam pelas expectativas de risco e retorno de cada investidor. Dessa forma, Rambo (2014) ressalta esses aplicadores levam mais em conta as suas emoções e expectativas em busca de maiores retornos e dessa forma acabam diminuindo as suas percepções de risco. Ademais, Barros e Felipe (2015) destacam que os indivíduos podem ignorar alguns componentes relevantes no momento de 
aplicar como forma de se tomar as decisões mais rapidamente.

Como forma de complementar o resultado discutido anteriormente, realizou-se uma análise de regressão linear simples, com o objetivo de verificar se a Participação de Pessoas Físicas (PPF), enquanto variável dependente, está associado ao Segmento de Governança Corporativa (SGC), variável independente. Nesse sentido, ao nível de confiança de 90\%, o Teste P-valor e o Teste F, ambos com nível de significância menor que 0,05 confirmaram a relação entre a variável dependente e a variável independente.

Considerando o poder de explicação da variável independente (SGC), aferiu-se um coeficiente de determinação (R2), igual a 0,0057, ou seja, $0,57 \%$ das variações no PPF são explicadas pelas variações no SGC. Diante desses dados, apesar da relação positiva entre as variáveis PPF e SCG, verifica-se estatisticamente que a segmentação em um nível de governança corporativa não é relevante para o investidor pessoa física, uma vez que, de acordo com o coeficiente de determinação, apenas $0,57 \%$ das variações no PPF são explicadas pelas variações no SGC, sendo que 99,43\% das variações nos níveis de participação de investidos pessoas físicas são explicadas por outros fatores diferentes do nível de governança corporativa e não presentes neste estudo. Assim, a RLS confirma dos resultados apresentados no quadro 6 (HAIR Jr., 2009).

\section{CONSIDERAÇÕES FINAIS}

A falta de estudos mais aprofundados em relação a este tema e a importância do investidor pessoa física para o mercado acionário foram as principais motivações para a construção deste estudo. $\mathrm{O}$ objetivo principal consistiu em analisar os investidores pessoa física no mercado de ações da BM\&FBOVESPA. Como resultado foi percebido que os maiores avanços em relação a participação de pessoas físicas na bolsa de valores de São Paulo ocorreram entre 2006 e 2010, de 219.634 para 610.915 aplicadores pessoas físicas, concomitantemente com os anos em que o Produto Interno Bruto (PIB) brasileiro obteve bons crescimentos e que a inflação se manteve estável. Ainda, que a participação da mulher, no que tange ao perfil dos aplicadores pessoas físicas, cresceu de 2002 e 2015, passando de 17,63\% em 2002, 15.030 mulheres, para 25,00\% em setembro de 2015, 133.613 mulheres. Entretanto, esse número ainda é bastante baixo, o que demonstra que políticas com incentivo a população feminina devem ser mais efetivos. Os aplicadores com idade entre 26 e 55 anos correspondem a 63,42\% dos aplicadores pessoas físicas. Verificou-se também que os estados de maior desenvolvimento econômico concentram a maioria dos investidores pessoas físicas, sendo que na região sudeste está 75\% dos aplicados pessoa física.

No que concerne aos setores em que existe maior participação de pessoas físicas, o setor de Tecnologia da Informação apresentou maior participação, seguindo a mesma linha observada em outros países. As diferenças entre os setores e os contextos em que cada um se encaixa foi responsável pelas discrepâncias entre os mesmos no que tange a participação de investidores individuais.

$\mathrm{Na}$ análise se maiores níveis de governança corporativa têm relação direta com a participação de investidores pessoas físicas nas empresas, foi verificado que o investidor pessoa física, na maioria das vezes, não observa o segmento de governança corporativa da empresa no momento de aplicar nela. Os investidores buscam maiores retornos de acordo com os riscos que pretendem assumir, dessa forma, os níveis de governança corporativa não têm grande influência em suas escolhas, a maioria dos aplicadores não observa se as empresas apresentam maior transparência ou accountability na hora de decidir aplicar ou não na organização.

Diante dos resultados aferidos, a elevação da participação de pessoas físicas no mercado de capitais demonstraria uma maior confiabilidade nas pessoas físicas em aplicarem no mercado acionário. 
Entretanto, principalmente devido os fatores macroeconômicos, como as taxas de juros elevadas existentes no Brasil, que resultam em grandes rentabilidades dos investimentos em renda fixa, como os títulos públicos, podem influenciam negativamente a participação de investidores individuas no mercado de ações. Com isso, só com a estabilização da economia e a redução da inflação o brasileiro poderá passar a ter como primeira opção o mercado de ações, diante do comportamento de aversão ao risco.

Com relação a principal dificuldade na realização deste estudo, a coleta e a adequação dos dados foram os principais empecilhos, pois foi necessário acessar a participação acionária de cada umas das empresas disponíveis e reunir dados dispersos. Ademais, como uma proposta para futuros estudos, ainda dentro da análise da participação de investidores individuais e da teoria das finanças comportamentais, surge a oportunidade de verificar os fatores que corroboram para a escolha de empresas para aplicação dos investidores individuais além dos setores de listagem, uma vez que os resultados deste estudo apesentaram que um maior nível de governança corporativa não é observado pelo aplicador individual.

\section{REFERÊNCIAS}

ANDRADE, G. A. R. ANDRADE, A. R. Governança Corporativa - Estudos de Escândalos Corporativos no Brasil e no Mundo. Simpósio de excelência em gestão e tecnologia. SEGeT 2005.

AMBINA, Associação Brasileira das Entidades dos Mercados Financeiros e de Capital. Iniciativas de educação financeira podem agora obter selo ENEF. Disponível em: $<$ http://portal.anbima.com.br/aanbima/noticias/Pages/2015/05/Iniciativas-de-educacao-financeira-podem-agora-obter-selo-da-Enef.aspx> . Acesso em 20 maio 2015.

ASSAF NETO, A. Mercado Financeiro. 5.ed. São Paulo: Atlas, 2003.

ASSAF NETO, A. Mercado Financeiro. 8. Ed. São Paulo: Atlas, 2008.

BARROS, T. de S.; FELIPE, I. J. dos S. Teoria do Prospecto: evidências aplicadas em finanças comportamentais. R. Adm FACES, Belo Horizonte. 2015.

BERNISTEM, P. A História do Mercado de Capitais: O Impacto da Ciência e da Tecnologia nos Investimentos. Rio de Janeiro: Elserier, 2008.

BM\&FBOVESPA, Bolsa de Valores, Mercadorias e Futuros de São Paulo. Valor de Mercado das Cias 2015. Disponível em:<

http://www.bmfbovespa.com.br/Sumario2.aspx $?$ menu=2\&sitemap=22214\&idioma=pt-br $>$. Acesso em 23 maio2015.

BM\&FBOVESPA. Conceitos Fundamentais Mercado de ações: Fundamentos e definições. 2011.

BM\&FBOVESPA . Comunicado ao Mercado. BM\&FBOVESPA divulga balanço de operações de abril de 2015.

BM\&FBOVESPA. Segmentos. Disponível em:http://www.bmfbovespa.com.br/pt-br/servicos/solucoespara-empresas/segmentos-de-listagem/bovespa-mais.aspx?idioma=pt-br. . Acesso em 23 maio2015.

BM\&FBOVESPA. Participação dos Investidores. Disponível em:< http://www.bmfbovespa.com.br/renda-variavel/BuscarParticipacaoInvestimento.aspx?Idioma=pt-br > . Acesso em 23 maio2015. 
BM\&FBOVESPA. Bovespa Mais. Disponível em: < http://www.bmfbovespa.com.br/pt$\mathrm{br} / \mathrm{servicos} /$ solucoes-para-empresas/segmentos-de-listagem/bovespa-mais.aspx?idioma=pt-br $>$. Acesso em 03 out. 2015.

BM\&FBOVESPA. Bovespa Mais Nível 2. Disponível em: $<$ http://www.bmfbovespa.com.br/pt$\mathrm{br} / \mathrm{servicos} /$ solucoes-para-empresas/segmentos-de-listagem/bovespa-mais-nivel2.aspx?idioma=pt-br $>$. Acesso em 03 out. 2015.

BM\&FBOVESPA. Visão Geral, Governança Corporativa Disponível em: < http://ri.bmfbovespa.com.br/static/ptb/visao-geral.asp?idioma=ptb> . Acesso em: 13 maio 2014.

BM\&FBOVESPA. Mercado de Balcão. Disponível em: < http://www.bmfbovespa.com.br/pt$\mathrm{br} /$ servicos/solucoes-para-negociacao/plataformas-de-negociacao/mercado-de-balcao.aspx ?idioma=pt-br >. Acesso em 05 nov. 2015.

BOTELHO, L. H. F. et al. Práticas de governança corporativa das companhias brasileiras operadas na bolsa de valores de Nova Iorque. Nucleus, Ituverava, v. 13, n. 1, p. 357-374, apr. 2016. ISSN 1982-2278. Disponível em: 〈http://www.nucleus.feituverava.com.br/index.php/nucleus/article/view/1602/2022>. Acesso em: 26 apr. 2017. doi:http://dx.doi.org/10.3738/1982.2278.1602 .

BRANT, D. In: IG ECONOMIA. Brasil empata com Chile e perde para Colômbia em pessoas físicas na Bolsa. 2012. Disponível em < http://economia.ig.com.br/mercados/2012-12-03/brasil-empata-com-chile-eperde-para-colombia-em-pessoas-fisicas-na-bolsa.html>. Acesso em 05 abr. 2015.

COLOMBO, J. A.; GALLI, O. C. Governança corporativa no Brasil: níveis de governança e rendimentos anormais. Revista Portuguesa e Brasileira de Gestão. 2010.

CORREIA, L. F. A.; FERNANDES, H.; LOUVET, P. Um índice de avaliação da qualidade da governança corporativa no Brasil. R. Cont. Fin. - USP, São Paulo, v. 22, n. 55, p. 45-63, jan./fev./mar./abr. 2011.

CORREA, Cristiane. Sonho Grande. Primeira Pessoa. Rio de Janeiro.2013.

DEBASTIANE. N. C. Aplicação do FGTS em fundos de privatização: Um estudo de caso. Florianópolis: UFSC, jun. 2004.

ESCAVASSA, K. M.; VIDOTTO, S. R. Mercado Acionário: O crescimento da participação de pessoas físicas na bolsa de valores na década de 2000. Revista das faculdades integradas Claretianas. v. 1, jandez. 2008.

FERREIRA, Vera Rita de Mello. A Cabeça do Investidor: Conhecendo suas emoções para investir melhor. Ed. Évora, 2011.

FILIPPO, 2008. In: NETO, J. B. Avaliação do controle de desempenho do investidor pessoa física catarinense no mercado de ações brasileiro. Departamento de Ciências Econômicas.

Florianópolis:UFSC, 2009.

FORTUNA, E. Mercado Financeiro: produtos e serviços. 10.ed. Rio de Janeiro: Qualitymark,1997.

GARCIA, F. A. Governança Corporativa. Monografia, Instituto de economia, Universidade Federal do Rio de Janeiro. 2005.

HAIR Jr., J. F. et al. Análise multivariada de dados. 6. ed. Porto Alegre: Bookman, 2009.

IBGC - INSTITUTO BRASILEIRO DE GOVERNANÇA CORPORATIVA. Governança Corporativa. Disponível em: < http://www.ibgc.org.br/index.php>. Acesso em: 20 maio 2014. 
IBGE - INSTITUTO BRASILEIRO DE GEOGRAFIA E ESTATÍSTICA. Produto Interno Bruto valores correntes. Disponível em: < http://seriesestatisticas.ibge.gov.br/series.aspx?t=produto-internobruto-br-valores-correntes\&vcodigo=SCN52 >. Acesso em: 17 mar. 2017.

\section{IBGE - INSTITUTO BRASILEIRO DE GEOGRAFIA E ESTATÍSTICA Índices de Preços ao}

Consumidor. Disponível em:

<http://www.ibge.gov.br/home/estatistica/indicadores/precos/inpc_ipca/defaulttab.shtm>. Acesso em: 17 mar. 2017.

KPMG International cooperative. Questões sobre empresas familiares: Fomentando o crescimento por meio de investidores individuais. Autores Independentes. 2014.

LANZARINI, J.J.S. et al. A popularização do mercado de ações brasileiro: as mudanças recentes na bolsa de valores. In: ENCONTRO NACIONAL DE ENGENHARIA DE PRODUCAO, 31. Anais... Belo Horizonte, 2011.

LEAL, R. P. C.; OLIVEIRA, J. de; SOLURI, A. F. Perfil da pesquisa em finanças no Brasil. Revista de Administração de Empresas (RAE), v. 43, n. 1, p. 91-104, 2003.

MATTA, I. B. da. Et al. Gestão da saúde pública: análise sobre os fatores condicionantes do desenvolvimento humano. Revista de Gestão em Sistemas de Saúde - RGSS, v. 5, n. 1. Jan./jun., 2016.

MELO, C.L.L.de; SILVA, C.A. T.. Finanças comportamentais: um estudo da influência da faixa etária, gênero e ocupação na aversão à perda . Revista de Contabilidade e Organizações, São Paulo, v. 4, n. 8, p. 3-23, apr. 2010. ISSN 1982-6486. Disponível em: 〈http://www.revistas.usp.br/rco/article/view/34756〉. Acesso em: 26 apr. 2016. doi:http://dx.doi.org/10.11606/rco.v4i8.34756.

NAKAMURA, W.T. et al . Determinantes de estrutura de capital no mercado brasileiro: análise de regressão com painel de dados no período 1999-2003. Rev. contab. finanç., São Paulo, v. 18, n. 44, p. 72-85, Aug. 2007 . Available from <http://www.scielo.br/scielo.php?script=sci_arttext\&pid=S151970772007000200007\&lng=en\&nrm=iso > access on 26 Apr. 2016. http://dx.doi.org/10.1590/S1519$\underline{70772007000200007 .}$.

NETO, J. B. Avaliação do controle de desempenho do investidor pessoa física catarinense no mercado de ações brasileiro. Florianópolis:UFSC, 2009.

OLIVEIRA, D. de P. R. de. Empresa Familiar: como fortalecer o empreendimento e otimizar o processo sucessório. 3. ed. São Paulo: Atlas, 2010.

OLIVEIRA, G.; PACHECO, M.. Mercado financeiro. São Paulo: Fundamento, 2010.

OS INVESTIDORES brasileiros no âmbito das finanças comportamentais. In: Concurso de Monografia CVM - BM\&FBOVESPA, 11. São Paulo. 2013.

PETERSON, R.L. Desvendando a mente do investidor: o domínio da mente sobre o dinheiro. Rio de Janeiro: Elsevier, 2008.

RAMBO, A. C. O perfil do investidor e melhores investimentos: da teoria à prática do mercado brasileiro. Florianópolis: UFSC, 2014.

RENICK, O.; SATARIANO, A. Ações de tecnologia atraem investidor nos EUA. 2014. DLM

INVESTA. Disponível em: < http://www.dlminvista.com.br/acoes-de-tecnologia-atraem-investidor-noseua/>. Acessado em: 08 nov. 2015.

RODRIGUES, A.C. A evolução do mercado de capitais brasileiro e o perfil do acionista minoritário no Brasil. SCIENTIA IURIS, Londrina, v.16, n.2, p.107-128, dez.2012. 
ROGERS, P.; SECURATO, J. R.; RIBEIRO, K. C. de S. Finanças comportamentais no Brasil: um estudo comparativo. Revista de Economia e Administração, v.6, n.1, 49-68p, jan./mar. 2007.

SAMPAIO, et al. A Governança Corporativa e o retorno das ações de empresas de controle familiar e de controle não familiar no Brasil. REGE, São Paulo, v. 21, n. 2, p. 219-234, abr.jun., 2014.

VIEIRA, M. M. F. Por uma boa pesquisa (qualitativa) em administração. In: VIEIRA, M.M.F.; ZOUAIN, D.M. (Org.) Pesquisa Qualitativa em Administração. Rio de Janeiro: FGV, 2006. P. p.13-28.

WALTER, S. A.; FREGA, J. R.; SILVA, W. V. da. Análise do comportamento e da percepção do investidor em relação ao risco sob a ótica da teoria de finanças comportamentais. Revista de Administração, v. 45, n. 2, art. 6, p. 172-187, 2010. 